\title{
STERNAL CLEFT AND SEGMENTAL FACIAL HEMANGIOMAS IN CHILDREN WITH PHACES SYNDROME: EFFECTIVENESS AND SAFETY OF CONSERVATIVE MANAGEMENT AND SURGICAL CORRECTION
}

DOI: 10.36740/WLek202006137

\author{
Iryna M. Benzar, Anatolii F. Levytskyi, Vlasii M. Pylypko \\ BOGOMOLETS NATIONAL MEDICAL UNIVERSITY, KYIV, UKRAINE
}

\begin{abstract}
The aim is to determine the risk factors of sternal cleft and segmental facial hemangiomas association in children with PHACES syndrome.

Materials and methods: 32 inpatient children with segmental facial hemangiomas and 19 children with sternal cleft were investigated concerning the Metry criteria of PHACES syndrome.

Results: In 6 children PHACE syndrome was diagnosed. Patients with bilateral $\$ 3$ hemangiomas $(50 \%, 3 / 6)$ had airway involvement with respiratory disorders. Conservative treatment was propranolol monotherapy $(66.7 \%, 4 / 6)$, or combination of prednisolone and propranolol $(33.3 \%, 2 / 6)$. Duration of propranolol treatment in children with PHACES syndrome was on an average $24.25 \pm 4.49$ months exceeding the duration of propranolol therapy in children with isolated soft tissue lesions ( $p<0.05)$. Primary surgical treatment of sternal cleft performed in children aged $2(n=3)$ and $4(n=1)$ months. The later period of surgery associated with the localization of hemangioma in the surgery region. Primary repair of sternal cleft was completed successfully in all cases; partial resection of the thymus made closure easier.

Conclusions: Primary surgical correction of a sternal cleft performed in young children provides good results. Partial resection of the thymus prevents respiratory and cardiovascular complications. Preoperative propranolol treatment averts the hemorrhagic complications in children with hemangiomas in surgical region.
\end{abstract}

KEY WORDS: PHACES syndrome, segmental hemangioma, propranolol, sternal cleft

Wiad Lek. 2020;73(6):1267-1271

\section{INTRODUCTION}

According to last updated of International Society for the Study of Vascular Anomalies (ISSVA) classification for vascular anomalies (2018), infantile hemangiomas has three patterns - focal, multifocal, and segmental [1]. 'Segmental" was defined as a hemangioma with plaque-like morphology, showing linear and/or geographic patterning over a specific cutaneous territory [2]. This type of hemangioma can associate with PHACES syndrome which is an acronym of Posterior fossa malformations, Hemangioma of the cervicofacial region, Arterial anomalies, Cardiac anomalies, Eye anomalies, and Sternal or abdominal clefting. It was first described in 1996 by Frieden and colleagues [3] and named PHACE syndrome. Two years later, Boulinguez et all changed the acronym to PHACES syndrome by adding sternal defects (S) [4].

Segmental hemangioma is the hallmark feature and is usually what leads the provider to consider a diagnosis of PHACE syndrome. Until 1996, cases of these complex abnormalities were described using a variety of acronyms: CHVD syndrome ("cutaneous hemangioma and vascular disorders"), ocular-cerebral-acral syndrome, 3C syndrome (cerebral hypoplasia, cavernous hemangioma, and coarctation of aorta), etc. Introduction of unified terminology and the multidisciplinary approach is the best option in diagnosis and treatment of patients with PHACE syndrome, as different organs and systems are affected, and there is a need for different methods of treatment.

\section{THE AIM}

The aim of the study is to determine the risk factors of association of sternal cleft and segmental facial hemangiomas in children with PHACES syndrome, evaluation of effectiveness and safety of conservative and surgical treatment.

\section{MATERIALS AND METHODS}

Retrospective analysis of clinical cases of 32 children with infantile facial hemangioma and 19 children with sternal cleft for the period January 1990 - March 2018 was performed. Including criteria were the diameter of hemangioma more than $5 \mathrm{~cm}$, diagnosis and treatment in a single hospital, age less than 6 months, the follow-up period more than 10 months. All children were investigated concerning the study protocol considering Metry 2009 criteria [5] of PHACES syndrome. Frontotemporal segment (S1) includes the lateral part of the forehead, the 
Iryna M. Benzar et al.

Table I. Clinical characteristics of 6 children with PHACES syndrome

\begin{tabular}{|c|c|c|c|c|c|c|c|}
\hline No & $\begin{array}{c}\text { Hemangiomas } \\
\text { topography }\end{array}$ & $\begin{array}{c}\text { Airway } \\
\text { involvement }\end{array}$ & $\begin{array}{c}\text { Brain } \\
\text { abnormalities }\end{array}$ & $\begin{array}{c}\text { Aortic and cardiac } \\
\text { abnormalities }\end{array}$ & Midline defects & Treatment & $\begin{array}{c}\text { Follow-up } \\
\text { (month) }\end{array}$ \\
\hline 1. & S2,3 left side & No & $\begin{array}{c}\text { Dandy-Walker } \\
\text { anomaly }\end{array}$ & $\begin{array}{c}\text { Coarctation } \\
\text { of the aorta, } \\
\text { left side aortic arch }\end{array}$ & No & $\begin{array}{c}\text { Propranolol, } \\
\text { cardio } \\
\text { surgery }\end{array}$ & 38 \\
\hline 2. & S3 bilateral & Yes & $\begin{array}{c}\text { Dandy-Walker } \\
\text { anomaly }\end{array}$ & & Sternal cleft & $\begin{array}{l}\text { Prednisolon, } \\
\text { propranolol }\end{array}$ & 33 \\
\hline 3. & $\begin{array}{l}\text { S1, S2 right side, } \\
\text { S3 bilateral }\end{array}$ & Yes & No & No & Sternal cleft & $\begin{array}{c}\text { Prednisolon, } \\
\text { propranolol, } \\
\text { surgery }\end{array}$ & 25 \\
\hline 4. & S3 bilateral & Yes & No & No & $\begin{array}{c}\text { Sternal cleft, } \\
\text { supraumbilical } \\
\text { raphe }\end{array}$ & $\begin{array}{l}\text { Propranolol, } \\
\text { surgery }\end{array}$ & 24 \\
\hline 5. & S1 bilateral & No & No & $\begin{array}{l}\text { Coarctation } \\
\text { of the aorta }\end{array}$ & No & $\begin{array}{c}\text { Propranolol, } \\
\text { cardio } \\
\text { surgery }\end{array}$ & 15 \\
\hline 6. & S1 left side & No & No & $\begin{array}{l}\text { Coarctation } \\
\text { of the aorta }\end{array}$ & Sternal cleft & $\begin{array}{c}\text { Propranolol, } \\
\text { surgery }\end{array}$ & 10 \\
\hline
\end{tabular}

lateral frontal and the anterior temporal portions of the scalp. Maxillary segment (S2) involves the upper part of the cheek and the upper lip. Mandibular segment (S3) applies to the preauricular region, mandible, chin, and lower lip. Clinical evaluations, including photographs, ultrasound investigation with a linear transducer in gray scale mode, color Doppler scan and partially in Doppler mode were used to document clinical characteristics of hemangioma concerning its different stages of growth. Mapping of segment location was performed in all cases using pre-defined segments which have been reported by Haggstrom et al. [6]. The next investigations included computed tomography $(\mathrm{CT})$, both native and intravenous enhanced; brain magnetic resonance imaging (MRI), cardiologic evaluation (electrocardiogram and echocardiography), neurological, and ophthalmological investigation. Statistical analysis was conducted using IBM SPSS Statistics Base (version 22). A value of $\mathrm{p}<0.05$ was considered statistically significant. Quantitative data are expressed as mean and with 95\% confidence interval (CI).

All studies were carried out in accordance with World Medical Association Declaration of Helsinki Ethical Principles for Medical Research Involving Human Subjects. It has been complied with the principle of privacy and respectfulness for the child's as an individual incapable of self-defense. The study was approved by Ethics Committee of Bogomolets National Medical University (protocol No 11,23/02/2016). All parents/ guardians have signed a written informed consent form.

\section{RESULTS}

Based on analysis of this study results, 6 of 32 children (18.75\%) with cervicofacial hemangiomas and 4 children of 19 with sternal cleft (21.05\%) met criteria for PHACE syndrome. A diagnosis of PHACE syndrome requires the presence of a face segmental hemangioma in addition to one big or more than two small criteria which are recognized as congenital structural defects of the brain, cerebrovasculature, cardiovasculature, eye, or sternum, or a supraumbilical raphe [7]. Congenital anomalies related to PHACES syndrome specific to each of our patients are described in table I.

All patients were girls. Bilateral segment 3 hemangioma was the most common, occurring in 3 patients (50\%). Two (33.3\%) had involvement of multiple segments, and one has left-sided S1 lesion (Fig. 1).

All patients with bilateral S3 involvement had subglottic and mediastinal hemangiomas with respiratory disorders. Stridor occurred in two patients in age of 10 and 12 weeks, other patient had resistant to antibacterial treatment dry cough. Other complications of hemangioma were ulcerations $(n=4)$, and visual axis obstruction due to upper eyelid lesion $(\mathrm{n}=1)$.

Except hemangiomas, patients had the next criteria of PHACE syndrome: posterior fossa malformations (variants of Dandy-Walker malformation) $(n=2)$, coarctation of the aorta $(n=2)$, right-sided aortic arch $(n=1)$, supraumbilical raphe $(\mathrm{n}=1)$, and four children $(66.7 \%)$ had superior sternal cleft (Fig. 1, 2). All patients were treated with systemic therapies, including propranolol monotherapy $(66.7 \%$, $4 / 6)$, and oral prednisolone plus propranolol $(33.3 \%, 2 / 6)$. Oral prednisolon was used in two patients with tracheal and mediastinal hemangioma and severe stridor as first line therapy before propranolol dose selection. Medical treatment was effective and we avoided tracheostomy in patients with airway obstruction. Oral administration of propranolol was started at $1 \mathrm{mg} / \mathrm{kg} / \mathrm{day}$ or $0.5 \mathrm{mg} / \mathrm{kg} / \mathrm{day}$ in children weighing less than $2500 \mathrm{~g}$ and was gradually increased to $2 \mathrm{mg} / \mathrm{kg} /$ day without any adverse reactions. For patient safety, treatment was started in the hospital with monitoring of blood pressure, heart rate (before and one 


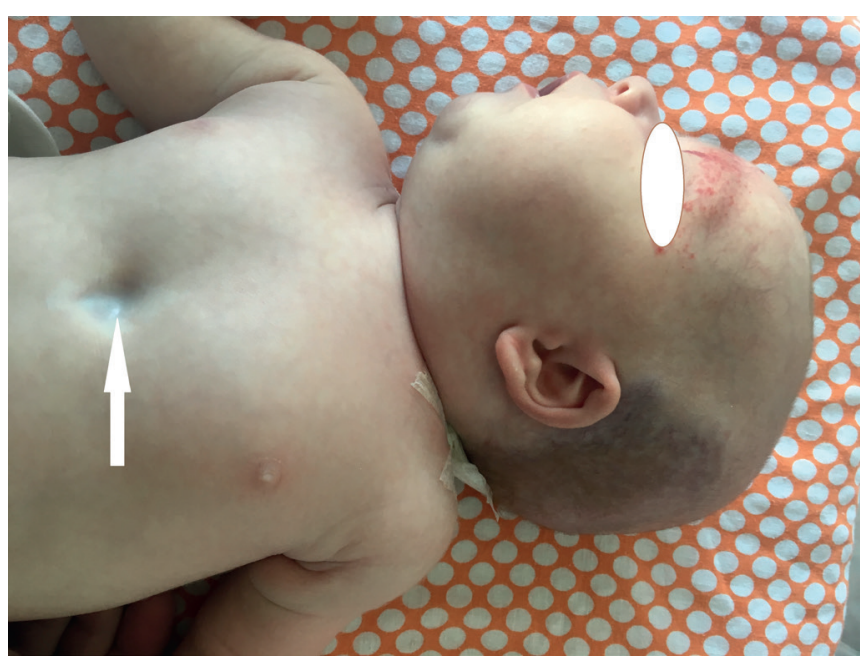

Fig. 1. One month patient with S1 (frontotemporal) right side hemangioma and sternal cleft
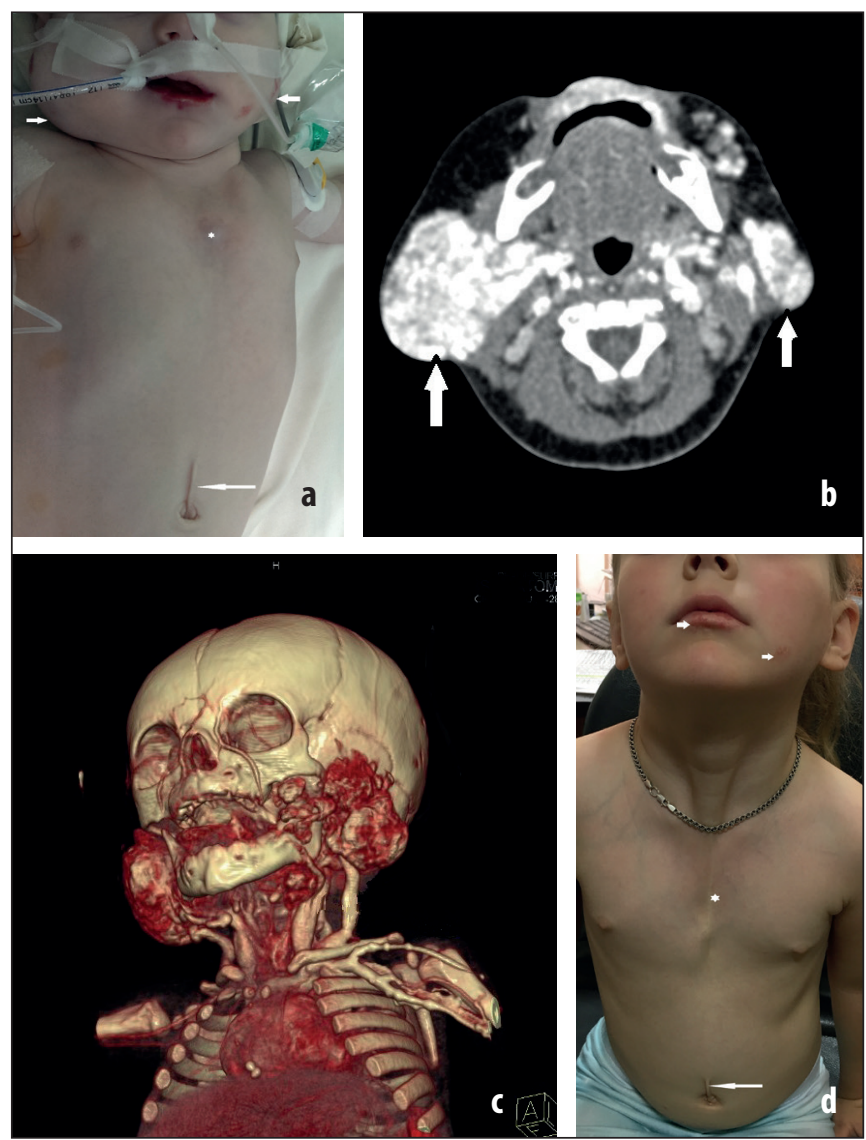

Fig. 3. a-d Patient with S3 bilateral hemangioma, subglotichemangioma with stridor, sternal cleft, and supraumbilical raphe. Picture before treatment (a). CT with intravenous enhanced (b). CT: 3D reconstruction shows the extension of hemangioma $(c)$. Picture after treatment; 3 years old $(d)$.

hour after taking the medication), determination of blood glucose once a day for 3-5 days during hospital staying. Patients with PHACE syndrome have the high risk of pediatric arterial ischemic stroke described first by Burrows et al. in 1998 [8] so neurological investigation is important.

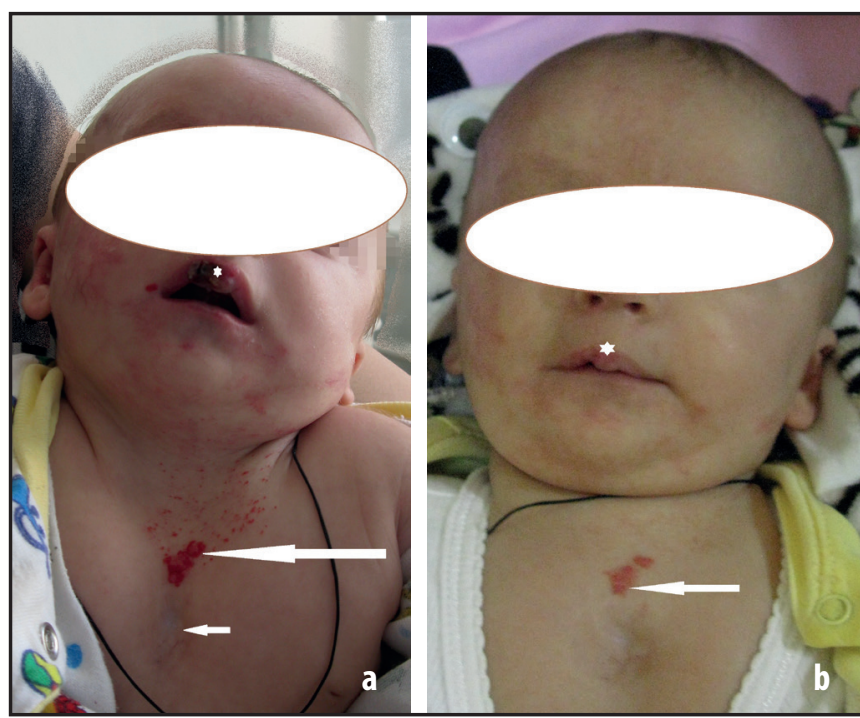

Fig. 2. a-b. Patient with PHACES syndrome, S1,2,3 segmental hemangiomas and hemangioma in sternal region. Picture before treatment, 2 month old (a). Picture after two month prednisolone treatment (b).

During inpatient care, mothers were trained in identify the adherence to medication, which also included informing them of alarming symptoms that may indicate complications of therapy, as well as signs of stroke. Propranolol was continued on an outpatient period at a defined dose. All children were assigned to one-month outpatient examinations. Duration of propranolol treatment in children with PHACE syndrome ranged from 18 to 36 months, with an average (24.25 \pm 8.49$)$ months exceeding the duration of propranolol therapy in children with isolated soft tissue infantile hemangiomas, lasted $(8.81 \pm 3.20)$ months $(\mathrm{p}<0.05)$.

Five children $(83.3 \%)$ with PHACE syndrome needed the surgery. There were two cases of cardiovascular malformations and four cases of sternal cleft. Two patients were operated in specialized cardiosurgery hospital. Patients with sternal clefts were treated in general pediatric hospital. We prefer early operation to achieve the primary closure. Two children were treated surgically at the age 2 month and one child aged 4 months. The later period of surgical correction for this patient is associated with the localization of hemangioma in the surgery region (Fig. $2 \mathrm{a}, \mathrm{b}$ ).

Preoperative administration of propranolol during two month was effective in decreasing the size of hemangioma, leading to the non-complicated surgical intervention. In one case sternal cleft correction was performed as simultaneous operation with surgery of coarctation of the aorta.

For surgery, all the patients were placed in a supine position, a midline skin incision was made and the defect and intact lower end of the sternum was exposed. Sternal bars were dissected from underlying intrathoracic fascia, parietal pleura, and pericardium. The sternal bars were cut transversely at the site of their join just above the costal arch. We usually perform a partial resection of the thymus to make closure easier. The sternal bars were approximated on the midline to complete restoration of the sternum by non-absorbable sutures. Follow-up period ranged from 10 
months to 3 years, with an average $(24.17 \pm 10.53)$ months. Primary repair of sternal cleft was completed successfully in all patients with PHACES syndrome, without any cardiovascular or respiratory impairment (Fig.3 a, b, c, d).

\section{DISCUSSION}

In one study PHACE patients represented $2.3 \%$ of all children with hemangiomas, and approximately $20 \%$ of those with segmental hemangiomas of the face [9]. Airway hemangiomas can be a life-threatening complication of PHACE syndrome with described frequency from 52\% [10] to $82 \%$ [9], it also characterized by a long duration of symptom persistence, from 13 to 76 months. In our study, respiratory tract involvement with impaired of their patency was diagnosed in $50 \%$ of children with PHACE syndrome. All children had S3 bilateral segmental hemangioma. Given the high rates of airways involvement, we recommend performing CT in all patients with segmental facial hemangiomas.

Following the first report in 2008, the non-selective beta-blocker propranolol was used as a first-line therapy for the treatment of "problematic" hemangiomas [11]. The method is effective and safe, but there are some caveats to prescribing propranolol in children with PHACES syndrome. Metry et al. published results of treatment of 32 patients with PHACE syndrome and arterial abnormalities, in 7 patients the authors observed a high risk of ischemic stroke [12]. Siegel et al. described possible mechanisms of cerebrovascular accident in patients with PHACES syndrome. It may be artery-to-artery embolisms, in which a thrombus forms in a stenotic or dysplastic cervical or cerebral artery, ischemia from reduced blood flow and inadequate cerebral perfusion, cardioembolisms due to structural abnormalities of the heart or proximal aorta [13]. There is a hypothesis that propranolol could increase the hemodynamic risks associated with an otherwise asymptomatic cerebral arteriopathy, in the worst case causing watershed infarct [12]. Fortunately, ischemic stroke is extremely rare complication of PHACE syndrome, and main efforts have focused on identifying which patients are at greatest risk. More than 50\% patients with PHACES syndrome need the surgery. Perioperative stress is a potential risk factor for strokes and seizures in patients with cerebrovascular and cardiac or aortic arch anomalies often occur in the same patients. It is essential to examine cerebral abnormalities, to check the glucose tolerance and electrolyte balance, performer the cardiological examination before starting propranolol in this category of patients.

Monitoring of patients with PHACE syndrome has been going on for over 20 years, new publications are emerging, and so-called "big" signs of the syndrome include pathological conditions that are not in the acronym. One of the major associate malformations that require surgical correction is sternal cleft [4]. This is a rare developmental pathology characterized by complete or partial defect of the chest bone and is the result of impaired fusion of the sternal plates during embryogenesis. In 1985 Kaplan LC et al hypothesized that a premature rupture of a chorionic or yolk sac during lowering of the heart causes damage to the mesodermal structures, which prevents midline fusion of the developing chest wall and cause the sternal cleft [14]. Involvement of skin tissues in this process of mesodermal injury has been suggested as an explanation for the association of hemangiomas and sternal cleft [15]. The disease is usually asymptomatic, but incomplete anterior wall of the chest skeleton is the cause of the paradoxical movement of this part of the chest with possible respiratory and cardiovascular disorders. Surgery is the treatment of choice. Although pathology is rare and publications are usually clinical cases, the authors claim that early correction is the best option. It allows easy approximation of bars and defect closure due to the chest's flexibility with a lesser risk of cardiac compression and respiratory distress [16].

\section{CONCLUSIONS}

Children with S3 segmental face hemangiomas have high risk of airway involvement. Primary surgical correction of a sternal cleft performed in young children provides good results. Partial resection of the thymus averts respiratory and cardiovascular complications. Preoperative propranolol treatment of hemangiomas prevents the hemorrhagic complications in children with hemangiomas in surgical region.

\section{REFERENCES}

1. International Society for the Study of Vascular Anomalies. ISSVA classification for vascular anomalies. Published April 2014. Revised May 2018. Available from: http://www.issva.org/UserFiles/file/ISSVAClassification-2018.pdf

2. Chiller K.G., Passaro D., Frieden I.J. Hemangiomas of infancy: Clinical characteristics, morphologic subtypes, and their relationship to race, ethnicity, and sex. Arch Dermatol. 2002;138:1567-76.

3. Frieden I.J., Reese V., Cohen D. PHACE syndrome. The association of posterior fossa brain malformations, hemangiomas, arterial anomalies, coarctation of the aorta and cardiac defects, and eye abnormalities. Arch Dermatol. 1996;132(3):307-11.

4. Boulinguez S., Teillac-Hamel D., Bédane C. et al. Cervicofacial hemangioma and a minor sternal malformation: inclusion in PHACES syndrome? Pediatr Dermatol 1998;15(2):119-21.

5. Metry D., Heyer G., Hess C. et al. Consensus statement on diagnostic criteria for PHACE syndrome. Pediatrics 2009;124:1447-56.

6. Haggstrom A.N., Lammer E.J., Schneider R.A. et al. Patterns of infantile hemangiomas: new clues to hemangioma pathogenesis and embryonic facial development. Pediatrics 2006;117(3):698-703.

7. Garzon, M., Epstein, L., Heyer et al. PHACE syndrome: Consensus- derived diagnosis and care recommendations. J Pediatr 2016; 178:24-33.

8. Burrows P.E., Robertson R.L., Mulliken J.B. et al. Cerebral vasculopathy and neurologic sequelae in infants with cervicofacial hemangioma: Report of eight patients. Radiology 1998; 207:601-7.

9. Haggstrom A.N., Skillman S., Garzon M.C. et al. Clinical spectrum and risk of PHACE syndrome in cutaneous and airway hemangiomas. Arch Otolaryngol Head Neck Surg 2011; 137(7):680-7.

10. Durr M.L., Meyer A.K., Huoh K.C. et al. Airway hemangiomas in PHACE syndrome. Laryngoscope 2012; 122 (10):2323-9. 
11. Léauté-Labrèze C., Harper J., Hoeger P. Infantile haemangioma. The Lancet 2017; 390(10089):85-94.

12. Metry D., Frieden I.J., Hess C. et al. Propranolol use in PHACE syndrome with cervical and intracranial arterial anomalies: collective experience in 32 infants. Pediatr Dermatol 2013;30(1):71-89

13. Siegel D., Tefft K., Kelly T. et al. Stroke in children with posterior fossa brain malformations, hemangiomas, arterial anomalies, coarctation of the aorta and cardiac defects, and eye abnormalities (PHACE) syndrome: a systematic review of the literature. Stroke. 2012; 43(6):1672-1674.

14. Kaplan L.C., Matsuoka R., Gilbert E.F. et al. Ectopia cordis and cleft sternum: evidence for mechanical teratogenesis following rupture of the chorion or yolk sac. Am J Med Genet. 1985; 21:187-202.

15. Ashok Raja J., Mathevan G., Mathiarasan K., Ramasubramaniam P. Closing the cleft over a throbbing heart: neonatal sternal cleft. BMJ Case Rep 2014; 4:1-4.

16. Karamustafaoğlu Y.A., Yanık F., Yörük Y. et al. Congenital Superior Sternal Cleft Repair Using Primary Closure. Balkan Med J 2019; 36(2):141-2.

The work is a fragment of the planned research work of the Pediatric Surgery Department of Bogomolets National Medical University "Development and implementation of enhanced surgical management for young children with vascular malformations, that involves minimal invasive and combined treatment options with pathogenetic feasibility " (state registration No. $0113 \mathrm{U} 004671$ ).

\section{ORCID and contributorship:}

Iryna M. Benzar - 0000-0001-7637-7769 A,D,E,F

Anatolii F. Levytskyi - 0000-0002-4440-2090 ${ }^{B, D}$

Vlasii M. Pylypko - 0000-0001-5506-0383 C,D

\section{Conflict of interest:}

The Authors declare no conflict of interest.

\section{CORRESPONDING AUTHOR}

Iryna M. Benzar

Department of Pediatric Surgery

Bogomolets National Medical University

Taras Shevchenko Boulevard, 13, 01601 Kyiv, Ukraine

tel: +380951295882

e-mail: Ira_benzar@yahoo.com

Received: 27.02 .2020

Accepted: 30.04 .2020 